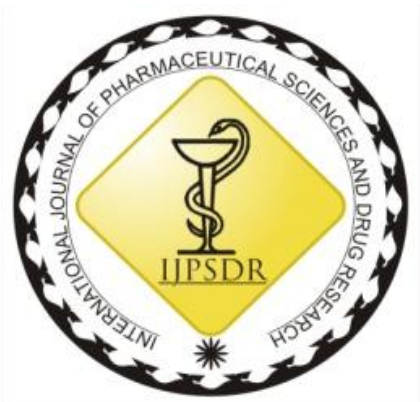

\author{
RESEARCH ARTICLE
}

ISSN: 0975-248X CODEN (USA): IJPSPP

$(\mathrm{cc})$ EY-NC-SA

\title{
Formulation and Characterization of Ondansetron Hydrochloride Matrix Tablets for Sustained Drug Delivery
}

\author{
P Gupta, V A Sethi, A W Siddiqui, L K Tyagi* \\ Lloyd Institute of Management and Technology (Pharm.), Greater Noida-201 306, Uttar Pradesh, India
}

Copyright (C) 2019 P Gupta et al. This is an open access article distributed under the terms of the Creative Commons Attribution-NonCommercialShareAlike 4.0 International License which allows others to remix, tweak, and build upon the work non-commercially, as long as the author is credited and the new creations are licensed under the identical terms.

\begin{abstract}
The objective of proposed work was to develop Ondansetron Hydrochloride (OND HCl) sustained release matrix tablets for the better treatment of vomiting for extended period of time. Sustained release matrix tablet is the drug delivery system that is designed to achieve a prolonged therapeutic effect by continuously releasing medication over an extended period of time after administration of single dose. The matrix tablets of OND HCl were prepared by direct compression method using varying ratio of hydroxy propyl methyl cellulose (HPMC) and ethyl cellulose. The bends of tablets were evaluated for bulk and tapped density, \% compressibility index and angle of repose and powder of all formulations blend exhibited that low interparticle friction and excellent flow characteristics. The prepared matrix tablets were then assessed for different physical tests like consistency of weight, thickness, hardness, friability, drug content and in vitro drug release. Each batch of the OND HCl matrix tablets were of good quality as to hardness, thickness, friability and \% medicament content. The in vitro drug release study was done for 2 hours by utilizing paddle technique in $0.1 \mathrm{~N} \mathrm{HCl}(\mathrm{pH} 1.2)$ as dissolution media and 6 hours using phosphate buffer ( $\mathrm{pH}$ 6.8) as dissolution media. The drug release study showed that all formulation FMT-1, FMT-2, FMT-3, FMT-4, FMT-5 and FMT- 6 were provide the drug release on sustained manner up to $8 \mathrm{hrs}$. Amongst the developed matrix tablets formulations, FMT-2 containing ethyl cellulose $(100 \mathrm{mg}$ ) was optimized as best because FMT-2 show highest drug release profile and promoting the sustained release of drug, which could potentially improve the patient compliance.
\end{abstract}

Keywords: Ondansetron HCl, HPMC, Ethyl cellulose, Matrix tablets, Sustained action.

*Corresponding author: Dr. Lalit Kumar Tyagi

Address: Lloyd Institute of Management and Technology (Pharm.), Greater Noida-201 306, Uttar Pradesh, India

Tel.: +91-9997306488

E-mail $\bowtie$ : lktyagi13@gmail.com

Relevant conflicts of interest/financial disclosures: The authors declare that the research was conducted in the absence of any commercial or financial relationships that could be construed as a potential conflict of interest.

Received: 26 June, 2019; Revised: 25 July, 2019; Accepted: 26 July, 2019; Published: 30 July, 2019

\section{INTRODUCTION}

Oral medication delivery is the most widely used route of administration because oral route is considered as uncomplicated, convenient and safe due to its simplicity of administration, patient acceptance, and cost-effective manufacturing process. It has been explored for systemic delivery of drugs via pharmaceutical products of different dosage form. Pharmaceutical products intended for oral delivery are mainly immediate release type or conventional drug delivery systems, which are intended for quick arrival of medication for rapid absorption. These quick release 
dosage forms have some restriction such as drugs with short half-life require repeated administration, which increase the chances of missing dose of drug leading to poor patient conformity. ${ }^{[1-2]}$ In order to overcome the drawbacks of conventional drug delivery systems, several technical advancements have led to the development of controlled/sustained drug delivery system that could reform routine of medication and provide a number of therapeutic benefits. The oral sustained delivery of medication is the most acceptable delivery system for patient acceptance, industrial application and economical but still it has several challenges to design a dosage form. The structure of oral sustained release systems is subject to several inter related variables of considerable importance such as the kind of delivery system, the illness being treated, the patient, the length of treatment and the properties of the medication. [3]

Ondansetron hydrochloride $(\mathrm{OND} \mathrm{HCl})$ is a serotonin 5-HT3 receptor antagonist and is an extensively exploit drug for the treatment of several remedial purposes like antiemetic particularly it is utilized in the prevention of post-operative sickness and vomiting and chemotherapy induced unsettled stomach and nausea or radiation induced queasiness and sickness. The main drawback of conventional dose of OND $\mathrm{HCl}$ is its oral bioavailability, which is about $60 \%$ and it has short biological half life which required frequent dosing (three times a day) led to patient incompliance. A sustained release formulation such as matrix tablets of $\mathrm{OND} \mathrm{HCl}$ is desired which would enable to control the nausea and vomiting for extended period of time. [4-7] The goal of this investigation was to prepare and characterize the matrix tablets of OND $\mathrm{HCl}$ for sustained release by utilizing HPMC and ethyl cellulose as polymer, in order to diminish dosing recurrence, to make sure safety and to improve effectiveness of the drug as well as patients conformity.

\section{MATERIALS AND METHODS}

\section{Materials}

Ondansetron hydrochloride (OND $\mathrm{HCl}$ ) was obtained as a gift sample from Beaukev Pharmaceuticals Private. Ltd., Mumbai, India. Ethyl cellulose, Hydroxy Propyl Methyl Cellulose (HPMC), Lactose, Talc and Magnesium stearate were obtained from Central Drug House (P) Limited, New Delhi, India. All other reagents used were of analytical grade.

\section{Methods}

\section{Preparation of matrix tablets of OND $\mathrm{HCl}$}

The matrix tablet formulations of OND $\mathrm{HCl}$ were prepared by direct compression method, utilizing ethyl cellulose and HPMC as a sustained release polymers in different ratio. Each tablet contains $5 \mathrm{mg}$ of OND $\mathrm{HCl}$ and other ingredients as listed in Table 1. HPMC and Ethyl cellulose polymers were chosen for its controlled/sustained release property. The requisite quantities of all powders were accurately weighed and passed through mesh 40 \# sieve. OND $\mathrm{HCl}$, ethyl cellulose, HPMC and lactose were physically blended until a homogeneous mixture was obtained. Magnesium stearate and talc was then added and mixed for $1 \mathrm{~min}$. Rotary tablet machine was used to compress the tablets of about $200 \mathrm{mg}$ average weight.

Table 1: Formulation composition of OND $\mathrm{HCl}$ sustained release matrix tablets

\begin{tabular}{ccccccc}
\hline Ingredients & \multicolumn{6}{c}{ Formulation Code } \\
\cline { 2 - 7 }$(\mathbf{m g})$ & FMT- & FMT- & FMT- & FMT- & FMT- & FMT- \\
& $\mathbf{1}$ & $\mathbf{2}$ & $\mathbf{3}$ & $\mathbf{4}$ & $\mathbf{5}$ & $\mathbf{6}$ \\
\hline OND HCl & 5 & 5 & 5 & 5 & 5 & 5 \\
Ethyl & 50 & 100 & 150 & - & - & - \\
Cellulose & & & & & & \\
HPMC & - & - & - & 50 & 100 & 150 \\
Lactose & 139 & 89 & 39 & 139 & 89 & 39 \\
Talc & 4 & 4 & 4 & 4 & 4 & 4 \\
Magnesium & 2 & 2 & 2 & 2 & 2 & 2 \\
Stearate & & & & & & \\
\hline
\end{tabular}

Evaluation of pre-compression parameters of powder mixture

The powder blends of each batch was subjected for evaluation of pre-compression parameters such as: bulk and tapped density, Carr's compressibility index (\%), Hausner's ratio and angle of repose in order to decide the flow property of powder bled. Bulk and tapped densities were estimated by utilizing a $10 \mathrm{ml}$ graduated measuring cylinder. The sample placed in the cylinder and the initial volume (bulk) noted. The cylinder was then, tapped 100 times and the final volume (tapped) again noted. The bulk and tapped densities were calculated from the proportion of their respective weight and volume.

Carr's index and hausner's ratio were computed by utilizing Eqs. 1 and 2, respectively.

Carr's compressibility index $(\%)=(\mathrm{Dt}-\mathrm{Db}) / \mathrm{Dt} \times 100$

Hausner's ratio $=\mathrm{Dt} / \mathrm{Db}$

Eqs .......... (2)

Where, Dt is tapped density and Db is the bulk density of the powder bled.

Angle of repose $(\theta)$ was derived for the powder mixture as an indicator for flowability characteristics. This was estimated according to the fixed funnel standing method. [8] The blend was poured through a funnel that can be raised vertically until a greatest cone height (h) was obtained. Radius of the heap (r) was estimated, and the angle of repose $(\theta)$ was determined according to Eqs. 3. [8-9]

$\theta=\tan ^{-1} \mathrm{~h} / \mathrm{r}$

Eqs ......... (3)

Determination of post-compression parameters of OND $\mathrm{HCl}$ matrix tablets

The prepared OND $\mathrm{HCl}$ matrix tablets were assessed for weight variation, hardness, thickness, \% friability, drug content (\%) and in vitro drug release study. [10-13]

Weight variation test

Weight variation test was performed in order to decide the \% variation in tablets. From every batch, 20 matrix tablets were arbitrarily taken and weighed independently to determine variation. The average \pm S.D. was determined. 


\section{Hardness test}

The hardness of matrix tablets was tested by utilizing Pfizer hardness tester. From each formulation batch, three tablets were arbitrarily taken and the values of hardness were determined.

\section{Thickness}

Vernier caliper was utilized for determination of thickness of the matrix tablets. From every formulation batch, three matrix tablets were arbitrarily taken and thickness was individually measured. Mean \pm S.D. were calculated.

\section{Friability test}

Roche friabilator was utilized for determination of $\%$ friability. The test was performed by firstly weighing of 10 tablets and after that transfer into friabilator. The friabilator was operated at $25 \mathrm{rpm}$ for 100 revolutions and tablets were weighed once again. Friability was computed as loss of percent in weight. The experiments are performed in triplicate.

Determination of drug content uniformity

The medicament content of the tablets was estimated spectrophotometrically. Three tablets were arbitrarily taken and then crushed into fine powder in the mortar for estimation of drug content. The weighed amount of powder containing equivalent to $5 \mathrm{mg}$ of $\mathrm{OND} \mathrm{HCl}$ was suspended and extracted in phosphate buffer $(\mathrm{pH}$ 6.8) for $12 \mathrm{~h}$ with shacking. This solution filtered using $0.45 \mu \mathrm{m}$ membrane filters. After suitable dilutions, drug content was analyzed by UV spectrophotometrically at a wavelength of $243 \mathrm{~nm}$. [11]

In vitro drug release study

The in vitro dissolution study was conducted by utilizing USP dissolution apparatus type II (Paddle method) at $50 \mathrm{rpm}$. Dissolution test was done for a total period of $8 \mathrm{~h}$ using simulated gastric fluid (SGF, 0.1 $\mathrm{HCl} \mathrm{pH} 1.2,900 \mathrm{ml}$ ) was used as dissolution medium for first $2 \mathrm{~h}$ and SIF (simulated intestinal fluid) phosphate buffer $\mathrm{pH} 6.8$ was used for the remaining test period. The temperature was kept at $37 \pm 0.5^{\circ} \mathrm{C}$. 5 $\mathrm{ml}$ of the sample was withdrawn at regular interval and replaced with the same volume of fresh dissolution medium. The samples withdrawn were filtered through $0.45 \mu$ membrane filter, and analyzed using UV-visible spectrophotometer at $243 \mathrm{~nm}$. All reading was carried out in triplicate. [8]

\section{RESULT AND DISCUSSION}

The purpose of study was to build up a sustained release delivery system of $\mathrm{OND} \mathrm{HCl}$. The sustained release matrix tablet formulations were effectively prepared by direct compression method, ethyl cellulose and HPMC as polymer.

The powder blends of different formulations were evaluated for loose bulk density, Tapped bulk density, Carr's compressibility index, Hausner's ratio and Angle of repose in order to predict the flow properties of formulations, results are shown in Table 2. The result of bulk density and Tapped density ranged from $0.42 \pm$ 0.002 to $0.55 \pm 0.003$ and $0.49 \pm 0.005$ to $0.65 \pm 0.03$, respectively. The carr's compressibility index and HR for all tablet formulations (excluding FMT-6 formulation) were under $15.47 \pm 0.975$ and $1.17 \pm 0.015$, correspondingly, which are within the normal acceptable and show good flow property. This is additionally substantiated by the estimation of angle of repose which was in the range from $19.36 \pm 1.052$ to $24.98 \pm 2.606$, indicates that low interparticle friction and excellent flow characteristics of all formulations, suggests that the all formulations can be effortlessly handled during processing of tablet manufacturing.

The weight variation test was performed under limit of weight variation according to pharmacopoeia specification. The average weight of the OND $\mathrm{HCl}$ matrix tablet formulations (FMT-1 to FMT-6) ranged from $192 \pm 1.13$ to $204 \pm 3.42 \mathrm{mg}$. The variation in weight was within the range of $<5 \%$ for all formulations. The average weight value of formulations is shown in Table 3. Thickness was found between 3.39 \pm 0.363 .59 to $3.59 \pm 0.31 \mathrm{~mm}$ for tablets. The result of hardness and \% friability of the tablets batches ranged from $3.9 \pm 1.10$ to $5.1 \pm 0.89 \mathrm{~kg} / \mathrm{cm}^{2}$ and $0.38 \pm 0.06$ to $0.79 \pm 0.04 \%$, respectively (Table 3 ). The results of hardness indicate that satisfactory mechanical strength of all formulations and matrix tablets batches show the value of $\%$ friability less than $1 \%$ indicates the excellent mechanical resistance. Drug content was found to be ranged from $89.81 \pm 1.13$ to $101.21 \pm 0.90 \%$ from different batches of the matrix tablet formulations, shown in Table 3. Matrix tablets formulation (FMT-2) with $100 \mathrm{mg}$ of ethyl cellulose polymer shows highest drug content i.e. $101.21 \pm 0.90 \%$. However, further increase in the concentration of polymers result in decrease in the drug content due to the reason that drug might not have been uniformly dispersed at higher concentration of polymers matrix. All batches of OND $\mathrm{HCl}$ matrix tablets were of good quality concerning to hardness, thickness, \% friability and drug content. All the formulations complied with pharmacopeial specification for weight variation and friability.

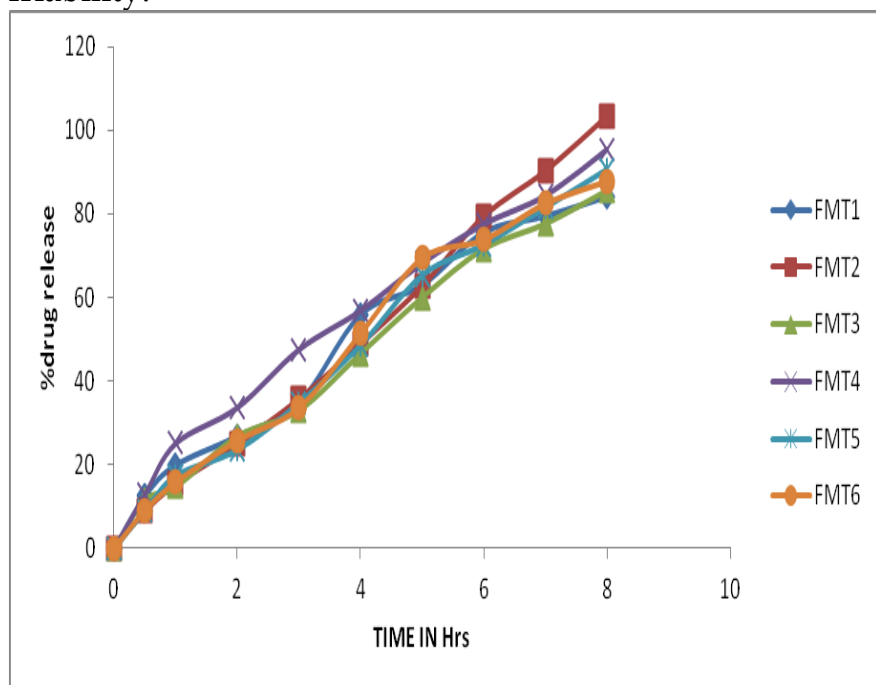

Fig. 1: In vitro cumulative $\%$ release of $\mathrm{OND} \mathrm{HCl}$ from matrix tablet formulations 
Table 2: Evaluation of pre-compression parameters of powder mixture

\begin{tabular}{ccccccc}
\hline S. No. & Formulation & $\begin{array}{c}\text { Bulk Density } \\
(\mathbf{g m} / \mathbf{c m} \mathbf{)}\end{array}$ & $\begin{array}{c}\text { Tapped Density } \\
\left(\mathbf{g m} / \mathbf{c m}^{\mathbf{3}}\right)\end{array}$ & $\begin{array}{c}\text { Cars Compressibility } \\
\text { Index } \mathbf{( \% )}\end{array}$ & $\begin{array}{c}\text { Hausner Ratio } \\
(\mathbf{H R})\end{array}$ & $\begin{array}{c}\text { Angle of Repose } \\
\left(\boldsymbol{\theta}^{\circ}\right)\end{array}$ \\
\hline 1 & FMT-1 & $0.55 \pm 0.003$ & $0.65 \pm 0.004$ & $15.47 \pm 0.975$ & $1.17 \pm 0.015$ & $22.07 \pm 1.793$ \\
2 & FMT-2 & $0.49 \pm 0.002$ & $0.55 \pm 0.006$ & $10.50 \pm 0.583$ & $1.11 \pm 0.011$ & $19.36 \pm 1.052$ \\
3 & FMT-3 & $0.47 \pm 0.002$ & $0.52 \pm 0.002$ & $9.56 \pm 0.057$ & $1.10 \pm 0.000$ & $23.76 \pm 2.466$ \\
4 & FMT-4 & $0.45 \pm 0.002$ & $0.49 \pm 0.005$ & $8.35 \pm 0.917$ & $1.09 \pm 0.010$ & $24.98 \pm 2.606$ \\
5 & FMT-5 & $0.44 \pm 0.002$ & $0.52 \pm 0.005$ & $15.38 \pm 0.017$ & $1.18 \pm 0.013$ & $23.29 \pm 1.376$ \\
6 & FMT-6 & $0.42 \pm 0.002$ & $0.55 \pm 0.005$ & $23.63 \pm 0.529$ & $1.3 \pm 0.007$ & $19.35 \pm 1.382$ \\
\hline
\end{tabular}

Table 3: Post-compression parameters of OND HCl matrix tablets

\begin{tabular}{cccccc}
\hline Formulation & Average Weight $\mathbf{( m g )}$ & Thickness $\mathbf{( m m})$ & Hardness $\left.\mathbf{( k g} / \mathbf{c m}^{\mathbf{2}}\right)$ & Friability (\%) & Drug Content (\%) \\
\hline FMT-1 & $201 \pm 1.50$ & $3.59 \pm 0.31$ & $4.4 \pm 0.68$ & $0.45 \pm 0.05$ & $98.83 \pm 1.03$ \\
FMT-2 & $204 \pm 3.42$ & $3.57 \pm 0.40$ & $4.5 \pm 1.02$ & $0.79 \pm 0.04$ & $101.21 \pm 0.90$ \\
FMT-3 & $199 \pm 2.24$ & $3.43 \pm 0.29$ & $5.1 \pm 0.89$ & $0.38 \pm 0.06$ & $92.32 \pm 2.70$ \\
FMT-4 & $201 \pm 1.30$ & $3.39 \pm 0.36$ & $4.8 \pm 0.93$ & $0.57 \pm 0.03$ & $99.05 \pm 1.31$ \\
FMT-5 & $192 \pm 1.13$ & $3.49 \pm 0.28$ & $3.9 \pm 1.10$ & $0.46 \pm 0.05$ & $89.81 \pm 1.13$ \\
FMT-6 & $199 \pm 3.18$ & $3.58 \pm 0.49$ & $4.6 \pm 0.91$ & $0.86 \pm 0.04$ & $94.59 \pm 0.98$ \\
\hline
\end{tabular}

Table 4: In vitro drug release profile of OND $\mathrm{HCl}$ matrix tablet formulations

\begin{tabular}{|c|c|c|c|c|c|c|}
\hline \multirow[b]{2}{*}{$\begin{array}{c}\text { Time } \\
\text { (h) }\end{array}$} & \multicolumn{6}{|c|}{ Cumulative \% Drug Release } \\
\hline & $\begin{array}{c}\text { FMT- } \\
1\end{array}$ & FMT-2 & $\begin{array}{c}\text { FMT- } \\
3\end{array}$ & $\begin{array}{c}\text { FMT- } \\
4\end{array}$ & $\begin{array}{c}\text { FMT- } \\
5\end{array}$ & $\begin{array}{c}\text { FMT- } \\
6\end{array}$ \\
\hline 0 & 0 & 0 & 0 & 0 & 0 & 0 \\
\hline 0.5 & 12.49 & 8.89 & 11.59 & 12.93 & 8.95 & 9.05 \\
\hline 1 & 19.89 & 15.36 & 14.69 & 25.12 & 17.40 & 15.83 \\
\hline 2 & 26.76 & 24.93 & 26.78 & 33.69 & 23.57 & 25.79 \\
\hline 3 & 34.68 & 35.78 & 32.98 & 47.58 & 34.76 & 33.68 \\
\hline 4 & 55.78 & 48.95 & 46.51 & 56.91 & 48.56 & 51.39 \\
\hline 5 & 62.85 & 62.81 & 59.89 & 68.31 & 65.30 & 69.47 \\
\hline 6 & 75.43 & 79.48 & 71.49 & 77.64 & 72.61 & 73.87 \\
\hline 7 & 79.31 & 90.35 & 77.53 & 84.49 & 81.49 & 82.49 \\
\hline 8 & 83.96 & 103.42 & 85.42 & 95.48 & 90.59 & 87.83 \\
\hline
\end{tabular}

In-vitro drug release study of all matrix sustained release tablet formulations was completed by utilizing buffer change method to mimic the GIT environment conditions. The dissolution medium was used $900 \mathrm{ml}$ $0.1 \mathrm{~N} \mathrm{HCl}(\mathrm{pH} 1.2)$ as simulated gastric fluid for the first $2 \mathrm{~h}$, followed by phosphate buffer as simulated intestinal fluid $(900 \mathrm{ml}, \mathrm{pH} 6.8)$ for the rest of $6 \mathrm{~h}$. The cumulative in-vitro release data for ondansetron $\mathrm{HCl}$ matrix sustained release formulations are shown in Table 4 and presented in Figure 1. It was seen that the cumulative \% drug release from prepared OND $\mathrm{HCl}$ matrix tablet formulations was found to be decreased with increase in the amount of polymers. This was occurred because the release of drug from the polymers matrix takes place after complete swelling of the polymers. The amount of polymers in the formulations increases, the time required to swell the polymers is also increases. The cumulative \% drug release from matrix sustained drug release tablet formulations FMT1, FMT-2, FMT-3, FMT-4, FMT-5 and FMT-6 was noted to be $19.89,15.36,14.69,25.12,17.40$ and $15.83 \%$, respectively in the first hour. All matrix sustained release tablet formulations FMT-1, FMT-2, FMT-3, FMT-4, FMT-5 and FMS-6 show cumulative \% drug release at the end of eight hours was found to be 83.96 $\%, 103.42 \%, 85.42 \%, 95.48 \%, 90.59 \%, 87.83 \%$, respectively. The release of drug depends not only on the nature of matrix but also upon the drug polymer ratio. It might be considered from the present investigation that slow, controlled and complete release of OND $\mathrm{HCl}$ over a period of $8 \mathrm{hrs}$ was obtained from matrix tablet (FMT-2) formulation containing $100 \mathrm{mg}$ of ethyl cellulose polymer. It is also apparent from the outcome that formulation FMT-2 is a better system for sustained release of OND $\mathrm{HCl}$.

This study presented a development of sustained release matrix tablet containing $\mathrm{OND} \mathrm{HCl}$ for the treatment of vomiting. Matrix tablets having higher efficacy for entrapment of drug and it have unique compressibility which offers a new effective way for producing mechanically strong tablets. Object of study was formulating the sustained matrix tablets for the treatment of vomiting. Matrix tablets were framed by utilizing direct compression technique. Excipients concentrations were optimized on the basis of assessment parameters of matrix tablets. In-vitro drug release studies of OND $\mathrm{HCl}$ matrix tablet formulations FMT-1- FMT-6 demonstrate the sustained release of drug. The matrix tablet formulation FMT-2 was best for delivery of drug which shows improved release profile than other formulations.

\section{ACKNOWLEDGEMENTS}

Author is thankful to Beaukev Pharmaceuticals Pvt. Ltd., Mumbai, India for providing Ondansetron Hydrochloride as a gift sample.

\section{REFERENCES}

1. Vyas SP, Khar RK. Novel carrier system. In: Vyas SP, Ed (s).Targeted and controlled drug delivery: Novel carrier system. New Delhi: CBS Publishers and distributors, 2008, pp. 41-43.

2. Brahmankar DM, Jaiswal SB. Biopharmaceutics and pharmacokinetics treatise. New Dehli: Vallabh Prakashan., 1995: pp. 335-337.

3. Chein YW. Novel drug delivery systems. New York : Marcel Dekker., 1992, pp. 43-47.

4. Bergström CA, Luthman K, Artursson P. Accuracy of calculated pH-dependent aqueous drug solubility. Eur J Pharm Sci. 2004; 22: 387-98.

5. Chaudhary A, Nagaich U, Gulati N, Sharma VK, Khosa RL. Enhancement of solubilization and bioavailability of poorly soluble drugs by physical and chemical modifications: A recent review. J Adv Pharm Edu Res. 2012; 2: 32-67. 
P Gupta et al. / Formulation and Characterization of Ondansetron Hydrochloride Matrix Tablets for Sustain......

6. Kumari DS, Vengatesh S, Elango K, Damayanthi RD, Deattu N, Christina P. Formulation and evaluation of floating tablets of ondansetron hydrochloride. Int J Drug Dev Res. 2012; 4: 265-74.

7. Kumar MP, Prasad MR, Pramod M, Reddy VP. Effect of permeation enhancer on ex-vivo permeation of Ondansetron $\mathrm{HCl}$ buccal tablets. Int J Pharm Sci Res. 2011; 2(11): 2841-45.

8. Strebel A, Siepmann J, Dashevsky A, Bodmeier R. pHindependent release of a weakly basic drug from waterinsoluble and soluble matrix tablets. J Control Release 2000; 67: 101-10.

9. Prajapati BG, Patel KR. Design and in-vitro evaluation of Nicorandil sustained release matrix tablets based on combination of hydrophilic and hydrophobic matrix system. Int. J. Pharm Sci Rev Res. 2010; 1(1): 33-38.
10. Tabandeh H, Mortazavi SA, Guilani TB. Preparation of sustained release matrix tablet of aspirin with ethyl cellulose, eudragit RS 100 and Eudragit S100 and studying the release profiles and their sensitivity to Tablet Hardness. Iranian J Pharma Res. 2003; 201-206.

11. Harish NM, Charyulu NR, Shenoy KRP. Formulation design and optimization of sustained release tablets of Terbutaline Sulphate. Ind J Pharm Edu Res 2011; 45(3).

12. Chithaluru K, Tadikonda R, Gollapudi R, Kandula KK. Formulation and in-vitro evaluation of sustained release matrix tablets of losartan potassium. Asian J Pharm Clin Res. 2011; 4(3): 18-22.

13. Jayanthi, Rashmi M, Shyamala B, Sateesha SB, Sindhu A. pHindependent controlled release swellable matrix tablets. IJRAP. 2011; 2: 577-80.

HOW TO CITE THIS ARTICLE: Gupta P, Sethi VA, Siddiqui AW, Tyagi LK. Formulation and Characterization of Ondansetron Hydrochloride Matrix Tablets for Sustained Drug Delivery. Int. J. Pharm. Sci. Drug Res. 2019; 11(4): 147-151. DOI: 10.25004/IJPSDR.2019.110408 